\title{
Сорбция некоторых лекарственных веществ белоозёрским глауконитом
}

\author{
Наумова Г.Н., Вениг С.Б., Чернова Р.К., Сержантов В.Г., \\ Селифонова Е.И., Сплюхин В.П.
}

Саратовский национальный исследовательский государственный университет им. Н.Г. Чернышевского, образовательно-научный институт наноструктур и биосистем, Саратов

Поступила в редакцию 30.06.2017 г.

Исследована сорбционная способность обогащенного (85\%-го) глауконита Белоозерского месторождения Саратовской области по отношению к лекарственным средствам: тетрациклину, доксициклину, дротаверину, амброксолу, анаприлину. Изучена кинетика сорбции, рассчитана сорбционная емкость для указанных веществ. Проведено геометрическое моделирование молекул лекарств. Обсужден возможный механизм сорбции с учетом характера групп на поверхности кремнеземных сорбентов, заряда поверхности глауконита, геометрии и гидрофобного фактора молекул сорбатов.

Ключевые слова: глауконит, сорбция, лекарственные вещества, кинетика сорбции

\section{Sorption of some medicinal substances by the Belozersk glauconite}

\author{
Naumova G.N., Venig S.B., Chernova R.K., Serzhantov V.G., \\ Selifonova E.I., Splyukhin V.P.
}

\author{
Saratov national research state university of $N$. G. Chernyshevsky, \\ Education and Research Institute of Nanostructures and Biosystems, Saratov
}

region have been investigated. Enriched glaukonite (85\%) has been received from glaukonits sand by method of dry magnetic separation. Researches on definition of such adsorptive characteristics as are conducted: measurement of specific surface area, the general porosity, distribution of a time on radiuses. The layered, nanostructured, scaly morphology of a surface of the enriched glaukonite is defined. The big sorption activity of this aluminosilicate is explained by such structure. The sorption ability of the enriched glaukonite is investigated by a spectophotometery methods in relation to some pharmaceutical medicines: to a tetracycline, doxycycline, drotaverin, ambroxol, anaprilin. For the specified substances kinetic curve sorptions are received and sorption capacities are calculated. Analyzing the received dependences, it is possible to judge time of approach of sorption balance in system glaukonite - pharmaceutical substances. Process of sorption of the substances stated above glaukonite proceeds quickly enough, so, within the first 5 seconds of sorption the most part of the dissolved sorbate passes into a sorbent phase $(\mathrm{R}=64.4-69, \%)$, and within 1 minute of sorption extent of extraction reaches $83.3 \%$. Further in system balance is established and there is a saturation of a sorbent. It is established that on sorption kinetics speed medicinal substances are rowed: drotaverin - doxycycline - tetracycline - anaprilin - ambroxol. Drotaverin is occluded much quicker than other substances. However the speed of sorption of all studied substances rather high that demonstrates course of physical adsorption. All studied substances, were occluded in the subacidic environment in the form of hydrochlorides which have in the molecule the protonated atom of nitrogen which is capable to be coordinated with oxygen electrons the silanolnykh and the siloksanovykh of groups of the glaukonit with formation of hydrogen communication. The positive charge of molecules of medicinal substances promotes also their rapprochement with a negatively charged surface of the glaukonite due to electrostatic interaction. Geometrical modeling of molecules of drugs is carried out. The possible mechanism of sorption taking into account cha- 
racter of groups on a surface of silica sorbents, a charge of a surface of the glaukonite, geometry and a hydrophobic factor of molecules of sorbates is discussed.

Keywords: glauconite, sorption, medicinal substances, sorption kinetics

\section{Введение}

Глауконит - широко распространённый в природе минерал, водный алюмосиликат железа, кремнезема и оксида калия непостоянного состава. Общие мировые запасы глауконита составляют около 35.7 млрд. тонн [1]. Интерес к изучению этого минерала постоянно возрастает как в России, так и за рубежом. Наряду с широким распространением, существенными достоинствами этого минерала также являются невысокая стоимость, высокие сорбционные и ионообменные свойства, не токсичность, термостойкость, зернистая структура и др. Благодаря всем этим качествам глауконит находит широкое применение в различных отраслях: экологии (очистка воздуха, почвы, воды [2-5].), сельском хозяйстве (кормовая добавка, минеральное удобрение [6-8].), энергетике (очистка нефтепродуктов, масел) [9], строительстве (строительные материалы, краска) [10], медицине (энтеросорбент, БАД), косметологии [11].

Сорбционные свойства глауконитов различных месторождений по отношению к ионам разных металлов изучались многими авторами. Показано, что глауконит является полифункциональным сорбентом, эффективно извлекающим из водных растворов ионы тяжёлых металлов: меди[12], никеля[13], свинца[14], железа(II) и (III)[15], кадмия[16], марганца[16], хрома[17]. Описана возможность использования глауконита в качестве фильтрующей загрузки в бытовых фильтрах для доочистки питьевой воды от катионов жёсткости $\left(\mathrm{Ca}^{2+}\right.$ и $\mathrm{Mg}^{2+)[8] . ~ В ~ р а б о т е ~[9] ~ и з у ч а л а с ь ~ с о р б-~}$ ция редкоземельных элементов (иттрия, гадолиния, лантана) из модельных растворов природным и модифицированным глауконитом а также возможность его применения для очистки от радиоактивного загрязнения.

Наряду с металлами сорбционная способность глауконита описана также к ряду органических веществ. Большое число работ посвящено изучению сорбционных свойств глауконита Бондарского месторождения Тамбовской области по отношению фенолу. Показано, что при варьировании условий сорбции очистку водных растворов от фенола на глауконите и его фракциях можно проводить с глубиной до $99.9 \%$ [20]. В статье [21] изучалась способность сорбции глауконитом жиров, содержащихся в сточной воде мясоперерабатывающих производств и показано, что сточная вода после очистки содержала на $16 \%$ меньше жиров. Перспективы использования глауконитового сорбента при очистке сточных хозяйственно-бытовых вод от органических загрязняющих веществ изучались в работе [22]. Эффективность очистки глауконитом загрязнённой воды от нефтепродуктов (дизельное топливо, мазут), бензапирена, фенола и его производных ( $o, m, n$-хлорфенол, 2,4-динитрофенол), диоксинов достигает 99,9 \%. Данные о сорбции лекарственных соединений на глауконите представлены в литературе в очень ограниченном количестве.

В настоящей работе исследована сорбция ряда лекарственных веществ (тетрациклина, доксициклина, дротаверина, анаприлина и амброксола) из водных растворов с помощью глауконита Белоозерского месторождения Саратовской области, общая характеристика которого дана в работе [23].

\section{Эксперимент}

В качестве сорбента использовали 85\%-ный концентрат глауконита, полученный из глауконитового песка Белоозерского месторождения методом сухой магнит- 
ной сепарации. Морфологические характеристики поверхности минерала изучали на сканирующем электронном микроскопе (CЭM) TESCAN MIRA II LMU. Для установления адсорбционных характеристик глауконита, проводили измерение удельной площади поверхности, общей пористости и распределения пор по радиусам методом Брюнера-Эммета-Теллера на быстродействующем анализаторе сорбции газов Quantachrome Instruments серии NOVA 2200 в автоматизированном режиме.

Исследовали сорбционную способность глауконита по отношению к ряду лекарственных препаратов (в форме таблеток) (табл. 1).

Таблица 1. Структурные формулы и некоторые характеристики используемых в работе лекарственных веществ

\begin{tabular}{|c|c|c|c|c|c|}
\hline № п/ா & Структурная формула & $\begin{array}{c}\text { М, } \\
\text { г/моль }\end{array}$ & $\log \mathrm{P}$ & $\begin{array}{c}\text { Число } \\
\text { доноров } \\
\text { водород. } \\
\text { связи }\end{array}$ & $\begin{array}{c}\text { Число ак- } \\
\text { цепторов } \\
\text { водород. } \\
\text { связи }\end{array}$ \\
\hline \multicolumn{6}{|c|}{ Тетрациклина гидрохлорид } \\
\hline 1 & $\cdot \mathrm{HCl}$ & 481 & -1.3 & 6 & 10 \\
\hline \multicolumn{6}{|c|}{ Доксициклина гидрохлорид } \\
\hline 2 & & 481 & -0.72 & 6 & 10 \\
\hline \multicolumn{6}{|c|}{ Дротаверина гидрохлорид } \\
\hline 3 & & 434 & 6.15 & 1 & 5 \\
\hline \multicolumn{6}{|c|}{ Амброксола гидрохлорид } \\
\hline 4 & & 415 & 2.6 & 3 & 3 \\
\hline \multicolumn{6}{|c|}{ Анаприлина гидрохлорид } \\
\hline 5 & & 296 & 3.48 & 2 & 3 \\
\hline
\end{tabular}

Тетрациклин (производитель: ОАО «Биохимик»). Активное вещество в 1 таблетке - 0.1 г тетрациклина гидрохлорида. Вспомогательные вещества: крахмал картофельный, целлюлоза, карбоксиметилкрахмал натрия, желатин 20 меш, тальк, кальция стеарат, сахароза, твин-80 (полисорбат 80), титана диоксид, краситель азорубин.

Доксициклин (производитель: ОАО «Борисовский ЗМП»). Активное вещество в 1 таблетке - 100 мг доксициклина гидрохлорида. Вспомогательные вещества: крахмал картофельный, лактозы моноргидрат, стеарат кальция. 
Дротаверин (производитель: ОАО «Лекфарм»). Активное вещество в 1 таблетке - 40 мг дротаверина гидрохлорида. Вспомогательные вещества: крахмал картофельный, тальк, лактоза.

Анаприлин (производитель: ОАО «Татхимфармпрепараты»). Активное вещество в 1 таблетке - 40 мг анаприлина гидрохлорида. Вспомогательные вещества: лактоза, крахмал картофельный, повидон (поливинил пирролидон среднемолекулярный), тальк, кальция стеарат.

Амброксол (производитель: ЗАО НПЦ "Борщаговский химикофармацевтический завод"). Активное вещество в 1 таблетке - 30 мг амброксола гидрохлорида. Вспомогательные вещества: лактоза, коповидон, аэросил, кальция стеаpat.

Сорбция глауконитом вышеуказанных лекарств исследовалась в статическом режиме при $\mathrm{T}=20^{\circ} \mathrm{C}$. Для этого навески глауконита по 0.5 г вносили в конические колбы вместимостью $100 \mathrm{~cm}^{3}$, заливали $25 \mathrm{~cm}^{3}$ исходного раствора лекарства $\left(\mathrm{C}_{\text {исх }}\right)$ и тщательно перемешивали на магнитной мешалке в заданном режиме времени $\left(\mathrm{t}_{\text {сорб}}\right)$. По истечении заданного времени отфильтровывали раствор и спектрофотометрически определяли остаточную концентрацию препарата в фильтрате $\left(\mathrm{C}_{\text {ост. }}\right)$.

\section{Обсуждение результатов}

Поверхность зёрен глауконита является сложной, слоистой, наноструктурированной (рис.1). Она составлена из чешуек различной формы и размеров с толщиной от 10 до 90 нм, расстояние между которыми составляло 10-200 нм.

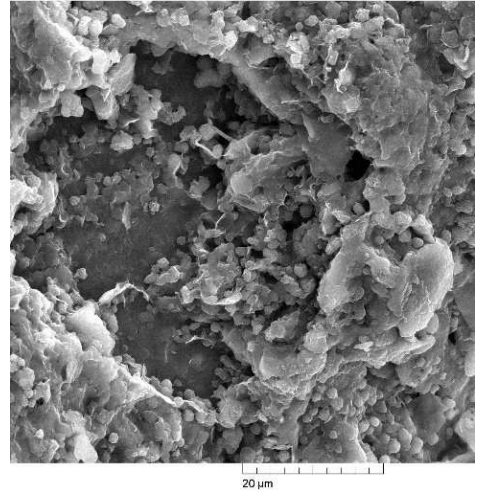

a

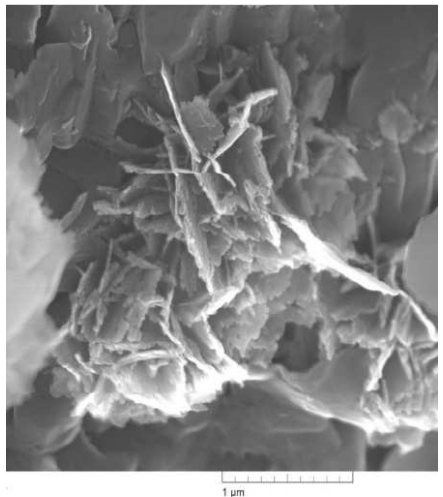

б

Рис. 1. Электронные микрофотографии поверхности зёрен глауконита:

а) ув. $5 \mathrm{kx}$, б) ув. $100 \mathrm{kx}$

Полученные изотермы адсорбции-десорбции азота на глауконите по IUPACклассификации относятся к изотермам IV типа, которые характеризуется наличием петли капиллярно-конденсационного гистерезиса, что является признаком наличия мезопор, размером от 2 до 50 нм (рис. 2).

Резкий подъём на изотерме при Р/Р0 близких к 1 указывает на небольшое наличие в образце крупных пор. При этом резкий подъём в области низких давлений идентичен форме изотермы I типа, которая характерна для микропористых сорбентов. Можно также отметить, что по классификации де Бура форма петли гистерезиса соответствует типу В и указывает на наличие щелевидных пор. Из адсорбционной и десорбционной ветвей изотерм получены следующие текстурные характеристики: удельная площадь поверхности - $22.78 \mathrm{~m}^{2} / \Gamma$, суммарный объём пор $-0.044 \mathrm{~cm}^{3} / \Gamma$. 


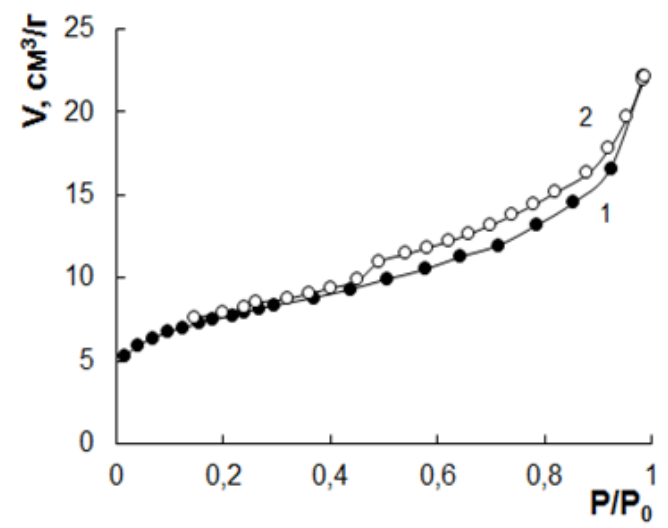

Рис. 2. Изотермы адсорбции(1)-десорбции(2) азота при 77 К на глауконите

На основании полученных результатов рассчитывали ёмкость глауконитового сорбента $\left(\mathrm{CE}\right.$, моль/г) по величинам исходной $\left(\mathrm{C}_{\text {исх }}\right)$ и равновесной $\left(\mathrm{C}_{\text {равн }}\right)$ концентраций тетрациклина с учётом массы сорбента:

$$
\mathrm{CE}=\frac{\left(\mathrm{C}_{\text {исх }}-\mathrm{C}_{\text {ост }}\right) \cdot \mathrm{V}}{\mathrm{m}},
$$

где $\mathrm{C}_{\text {исх }}$ - концентрация лекарственного вещества до сорбции, моль/дм ${ }^{3} ; \mathrm{C}_{\text {ост }}$ - концентрация лекарственного вещества после сорбции, моль/дм ${ }^{3} ; \mathrm{V}$ - объём раствора, из которого проводили сорбцию $\left(25 \mathrm{~cm}^{3}\right) ; \mathrm{m}$ - масса сорбента $(0.5$ г).

Рассчитанные значения сорбционной емкости глауконита к исследуемым веществам приведены в таблице 2.

Таблица 2. Значения сорбционной емкости глауконита для исследуемых веществ

\begin{tabular}{|c|c|c|c|}
\hline Лекарственное вещество & $\mathrm{C}_{\text {исх. }}$, моль/л & Время сорбции, мин & СЕ, ммоль/Г \\
\hline Тетрациклин & $5.20 \cdot 10^{-5}$ & 30 & $(1.97 \pm 0.04) \cdot 10^{-3}$ \\
\hline Доксициклин & $5.20 \cdot 10^{-5}$ & 30 & $(2.66 \pm 0.03) \cdot 10^{-3}$ \\
\hline Анаприлин & $2.70 \cdot 10^{-5}$ & 60 & $(1.08 \pm 0.06) \cdot 10^{-3}$ \\
\hline Дротаверин & $9.22 \cdot 10^{-5}$ & 20 & $(4.27 \pm 0.08) \cdot 10^{-3}$ \\
\hline Амброксол & $3.61 \cdot 10^{-5}$ & 60 & $(1.06 \pm 0.04) \cdot 10^{-3}$ \\
\hline
\end{tabular}

Степень извлечения сорбата $\mathrm{R}$ оценивали по формуле:

$$
\mathrm{R}=\frac{\left(\mathrm{C}_{\text {исх }}-\mathrm{C}_{\text {ост }}\right)}{\mathrm{C}_{\text {исх }}} \cdot 100 \%,
$$

где $\mathrm{C}_{\text {исх }}$ и $\mathrm{C}_{\text {ост }}$ - концентрация тетрациклина до и после сорбции, соответственно. Результаты расчёта $\mathrm{R}(\%)$ при разном времени сорбции представлены на рисунке 3.
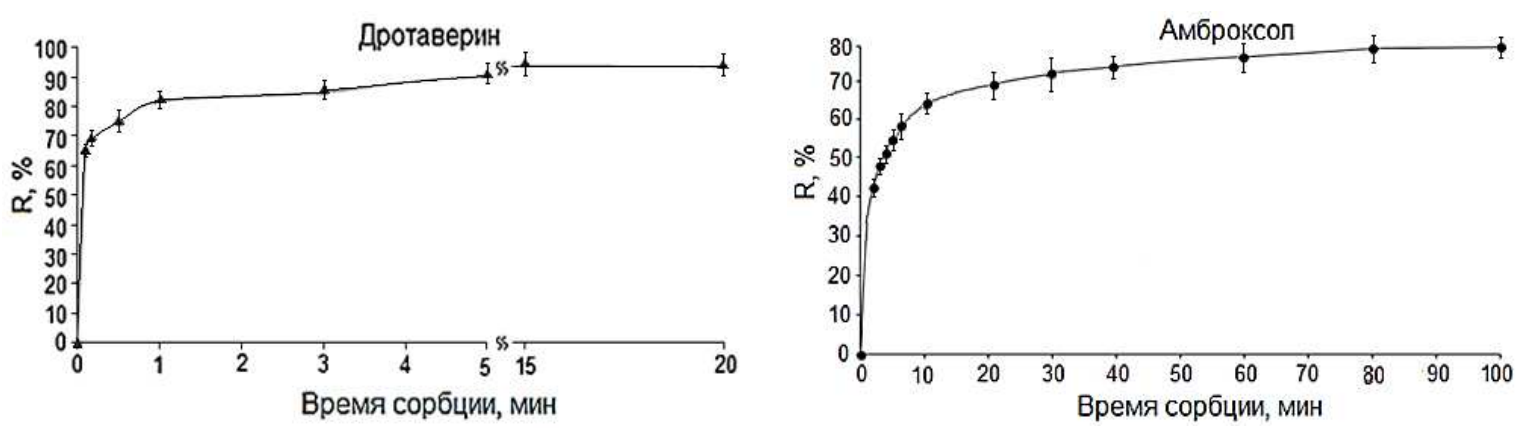

Рис. 3. Зависимость степени сорбции лекарственных веществ обогащённым глауконитом от времени сорбции 
Проведённое изучение кинетики сорбции даёт возможность судить о времени наступления сорбционного равновесия в системе глауконит-лекарственное вещество. Анализируя полученные зависимости, можно заключить, что процесс сорбции дротаверина глауконитом протекает практически мгновенно. Так, уже в течение первых 5 секунд сорбции большая часть растворенного дротаверина переходит в фазу сорбента ( $\mathrm{R}=64.4 \%)$, а в течение 1 минуты сорбции степень извлечения достигает 83.3\%. Дальнейшее увеличение времени сорбции до 20 минут не приводит к существенному увеличению сорбционной ёмкости, т.е. в системе устанавливается равновесие и происходит насыщение сорбента. Далее по кинетике сорбции следуют антибиотики тетрациклин и доксициклин, степень извлечения этих веществ при 5 минутах сорбции достигает 65.2 и 69.7\% соответственно, затем процесс насыщения сорбента замедляется и к 30 минутам практически не изменяется. Процесс сорбции анаприлина и амброксола идёт наиболее медленно в основном в течение 40 минут, при этом степень извлечения составляет 72.4 и $70.5 \%$ соответственно. Таким образом, по скорости кинетики сорбции лекарственные вещества располагаются в ряд: дротаверин>доксициклин/тетрациклин>анаприлин/амброксол, причём дротаверин сорбируется намного быстрее остальных веществ. Однако скорость сорбции всех исследуемых веществ достаточно высокая, что свидетельствует о протекании физической адсорбции.

Обсуждая возможный механизм сорбции указанных лекарственных соединений следует рассмотреть строение поверхности глауконита. Главной составной частью глауконита является кремнезём. Кремнезёмы содержат на своей поверхности свободные силанольные группы, которые частично ионизированы, в результате чего поверхность сорбента насыщена водой и несёт некоторый отрицательный заряд. На поверхности кремнезёмов находятся также силоксановые группы, обладающие протоноакцепторными свойствами, а также геминальные и вициальные силанольные группы, действующие как доноры протонов (рис. 4). В связи с этим можно предположить, сто структуры подобного типа легко сорбируют соединения, несущие положительный заряд.

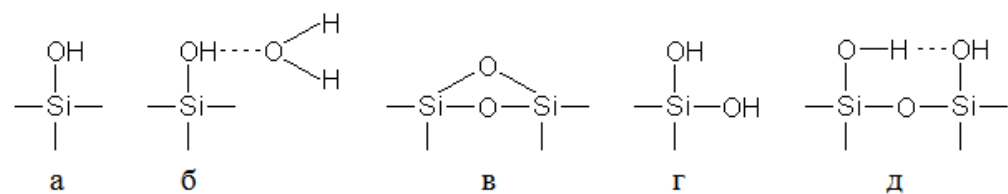

Рис. 4. Группы находящиеся на поверхности кремнезёмных сорбентов:

а - силанольные (свободные, отдельно стоящие ОН-группы); б - силанольные группы, связанные с водой водородной связью (физически-связанная вода); в - силоксановые группы; г - геминальные силанольные группы (связанные с одним атомом кремния); д - вицинальные силанольные группы (соседние ОН-группы, связанные между собой водородной связью).

Все изучаемые вещества, сорбировались в слабокислой среде в форме гидрохлоридов, которые имеют в своей молекуле протонированный атом азота (акцептор электронов), который способен координироваться с электронами кислорода силанольных и силоксановых групп глауконита с образованием водородной связи. Положительный заряд молекул лекарственных веществ способствует также сближению их с отрицательно заряженной поверхностью глауконита за счет электростатического взаимодействия. В результате такого сближения становится возможным и гидрофобное взаимодействие между гидрофобными частями молекул сорбатов и гидрофобными участками глауконитового сорбента, как это видно на примере дротаверина, имеющего наибольшее значение $\log$ P. 


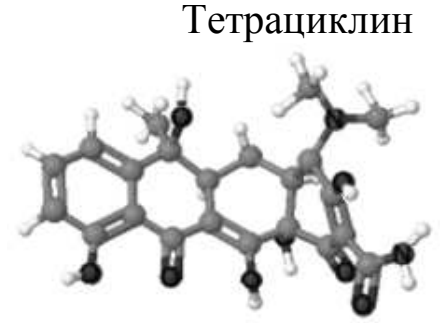

Дротаверин

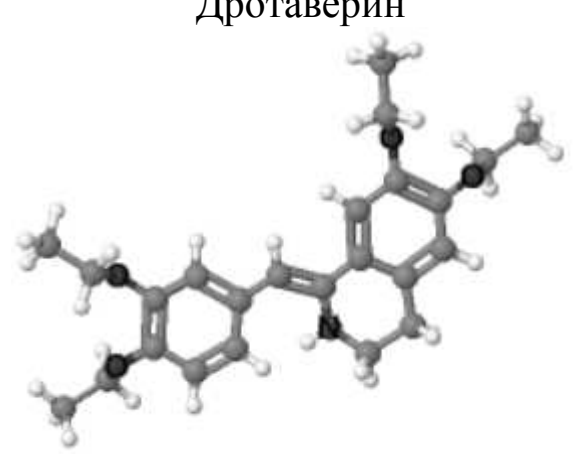

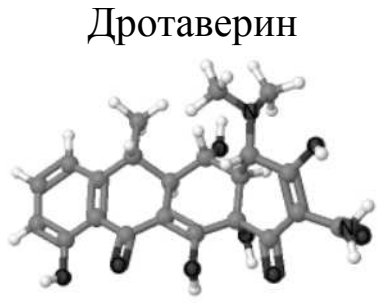

Анаприлин

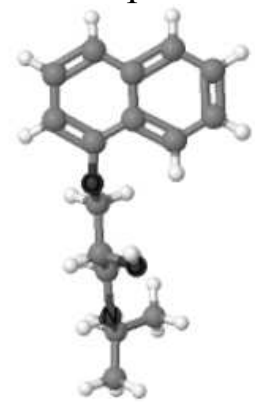

Амброксол

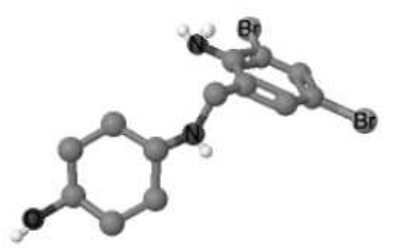

Рис. 5. Пространственные 3 D структуры лекарственных соединений

Также нами было рассмотрено влияние на сорбцию геометрии молекул лекарств (рис. 5). Для этого моделировались 3 D пространственные структуры лекарственных соединений. Можно отметить, что дротаверин, молекула которого лучше всего сорбируется на глауконите, имеет плоское строение, что может способствовать его сорбции на поверхности глауконита.

\section{Заключение}

Представленные результаты свидетельствуют о высокой сорбционной способности и большой скорости сорбции глауконитом сорбатов исследованных лекарственных веществ, относящихся к разным классам химических соединений, имеющих разные реакционноспособные центры, разную геометрию и гидрофобность. Однако общим для сорбатов является близость величин их молярной массы, нахождение в растворе в виде положительно заряженных ионов. Можно полагать, что имеет место смешанный механизм сорбции, содержащий физическую и химическую компоненты, который еще предстоит детализировать, однако важным является определенная универсальность этого природного сорбента, который способен сорбировать большое количество разных по природе органических сорбатов.

К практическим результатам проведенного исследования можно отнести рекомендацию: исследовать применение глауконита для доочистки сточных вод конкретных фармацевтических производств.

\section{Список литературы}

1. Бетехтин А.Г. Курс минералогии. М. Гос. изд-во по геологии и охране недр, 1956. 558 с.

2. Никитина Н.В., Комов Д.Н., Казаринов И.А., Никитина Н.В. // Сорбционные и хро- матографические проиессы. 2016. Т. 16. № 2. C. 191-199.

3. Печенюк С.И. // Сорбиионные и хроматографические процессы. 2008. Т. 8. № 3. С. 380-429. 
4. Лы Тхи Иен, Хохлов В.Ю., Селеменев В.Ф., Бельчинская Л.И. // Сорбиионные и хроматографические процессы. 2011. Т. 11. № 3. С. 382-390.

5. Наумова Г.Н., Селифонова Е.И., Чернова Р.К., Вениг С.Б. и др. // Сорбиионные и хроматографические прочессы. 2017. Т. 17. № 1. C. 141-147.

6. Наумова Г.Н., Гусакова Н.Н., Чернова Р.К., Селифонова Е.И. и др. // Известия Саратовского университета. Сер. Химия. Биология. Экология. 2016. Т. 16. вып. 4. С. 388392.

7. Колягин Ю.С., Мешков В.Н. // Картофель и овощи. 2008. № 8. С. 8-13.

8. Карнаухов Ю.А. // Известия Оренбургского государственного аграрного универcumema. 2012. T. 33. № 1. C. 130-132.

9. Корнев А.Ю., Тупотилов Н.Н, Остриков В.В., Алибаев Б.Т. // Наука в центральной России. 2014. T. 2.№ 8. C. 48-53.

10. Левицкий И.А., Папко Л.Ф., Павлюкевич Ю.Г., Баранцева С.Е. // Стекло и керамика. 2005. № 6. С. 22-25.

11. Гапарова А.Ш., Чолпонбаев К.С. // Вестник Кыргызской гос. медииинской академии им. И.К. Ухунбаева. 2013. Вып. 3. С. 28-33.

12. Вигдорович В.И., Цыганкова Л.Е., Николенко Д.В., Акулов А.И. // Сорбичонные и хроматографические прочессы. 2010. Т. 10. № 6. C. 29-32.

13. Крупнова Т.Г., Кострюкова А.М., Ракова О.В., Григорьева Е.А. // Вестник Саратовского государственного технического университета. Серия: Экология. 2011. Вып. 3. C. 296-304.

\section{References}

1. Betektin A. G. The course of mineralogy. M., Gos. Publishing house on geology and conservation of mineral resources, $1956,558 \mathrm{p}$.

2. Nikitina N.V., Komov D.N., Kazarinov I.A., Sorbtsionnye i khromatograficheskie protsessy, Vol. 16, No 2, pp. 191-199.

3. Pechenyuk S.I. Sorbtsionnye i khromatograficheskie protsessy, 2008, Vol. 8, No 3, pp. 380-429.

4. Ly Thi Yen, Khokhlov V.Yu., Selemenev VF, Belchinskaya L.I., Sorbtsionnye i khromatograficheskie protsessy, 2011, Vol. 11, No 3, pp. 382-390.

5. Naumova G.N., Selifonova E.I., Chernova R.K., Venig S.B. et al., Sorbtsionnye i khroma-
14. Вигдорович В.И., Цыганкова Л.Е., Николенко Д.В., Акулов А.И. и др. // Сорбциионные и хроматографические прочессы. 2010. T. 10. № 1. C. 121-126.

15. Сухарев Ю.И., Кувыкина Е.А. // Известия Челябинского научного иентра УрО РАН. Серия: Химия и Биоэкология. 2002. № 1. C. 62-66.

16. Синельцев А.А., Губина Т.И., Антонова И.А, Сержантов В.Г. // Вестник Саратовского государственного технического университета. Серия: Химическая физика. 2012. T. 31. № 10. С. 29-32.

17. Мартемьянов Д.В., Галанов А.И., Юрмазова Т.А. // Журнал фундаментальных исследований. 2013. Вып. 8. С. 666-670.

18. Сухарев Ю.И., Крупнова Т.Г., Григорьева Е.А., Титова Е.Н. и др. // Известия Челябинского научного иентра УрО РАН. Серия: Химия и Биоэкология. 2005. Вып. 3. С. 80-84.

19. Таубаева Э.С., Джусипбеков У.Ж., Жунусов С.М. // Вестник Казанского технического университета. 2010. Вып. 6. С.74-165.

20. Вигдорович В.И., Циганкова Л.Е., Акулов А.И. // Сорбиионные и хроматографические прочессы. 2011. Т. 11. № 2. С. 256-262.

21. Горельникова Е.А., Ковалёва С.В., Карпунина Л.В., Сплюхин В.П. и др. // Аграрный научный журнал. Сер. Естественные науки. 2016. № 11. С. 18-21

22. Ламскова М.И., Новиков А.Е. // Известия Волгоградского государственного технического университета. 2014. Т. 7. № 1. С. $77-80$

23. Вениг С. Б., Сержантов В. Г., Чернова Р. К., Доронин С. Ю. и др. // Бутлеровские сообщеения. 2014. Т. 39. № 8. С. 17-26.

tograficheskie protsessy, 2017, Vol. 17, No 1, pp. 141-147.

6. Naumova G.N., Gusakova N.N., Chernova R.K., Selifonova E.I. et al., Proceedings of the Saratov University. Ser. Chemistry. Biology. Ecology, 2016, Vol. 16, No 4, pp. 388-392.

7. Kolyagin Yu.S., Meshkov V.N., Potatoes and vegetables, 2008, No 8, pp. 8-13.

8. Karnaukhov Yu.A. ,Proceedings of the Orenburg State Agrarian University, 2012, Vol. 33, No 1, pp. 130-132.

9. Kornev A.Yu., Tupotilov NN, Ostrikov VV, Alibaev B.T., Science in Central Russia, 2014, Vol. 2, No 8, pp. 48-53.10. 
10. Levitsky I.A., Papko L.F., Pavlyukevich Yu.G., Barantseva S.Ye., Glass and ceramics, 2005. No 6, pp. 22-25.

11. Gaparova A.Sh., Cholponbaev K.S., Bulletin of the Kyrgyz State Medical Academy. I.K. Uhunbaeva, 2013, Vol. 3, pp. 28-33.

12. Vigdorovich V.I., Tsygankova L.E., Nikolenko D.V., Akulov A.I., Sorbtsionnye i khromatograficheskie protsessy, 2010, Vol. 10, No 6, pp. 29-32.

13. Krupnova T.G., Kostryukova A.M., Rakova O.V., Grigorieva E.A., Bulletin of the Saratov State Technical University. Series: Ecology, 2011, Vol. 3, pp. 296-304.

14. Vigdorovich V.I., Tsygankova L.E., Nikolenko D.V., Akulov A.I. et al., Sorbtsionnye $i$ khromatograficheskie protsessy, Vol. 10, No 1, pp. 121-126.

15. Sukharev Yu.I., Kuvykina E.A., Proceedings of the Chelyabinsk Scientific Center of the Ural Branch of the Russian Academy of Sciences. Series: Chemistry and Bioecology, 2002, No 1, pp. 62-66.

16. Sinel'tsev AA, Gubina TI, Antonova IA, Sergeantov V.G., Bulletin of the Saratov State Technical University. Series: Chemical Physics, 2012, Vol. 31, No 10, pp. 29-32.

Вениг Сергей Борисович - д.ф.-м. наук, професcop, заведующий кафедрой материаловедения, технологии и управления качеством, Саратовский национальный исследовательский государственный университет им. Н.Г. Чернышевского, Саратов

Чернова Римма Кузьминична - д.х.н., профессор кафедры аналитической химии и химической экологии химического факультета, Саратовский национальный исследовательский государственный университет им. Н.Г. Чернышевского, Саратов

Сержантов Виктор Геннадиевич - к.ф.-м.н., заведующий базовой кафедрой сорбционных материалов, Саратовский национальный исследовательский государственный университет им. Н.Г. Чернышевского, Саратов

Сплюхин Владимир Петрович - ассистент базовой кафедры сорбционных материалов, Саратовский национальный исследовательский государственный университет им. Н.Г. Чернышевского, Саратов

Селифонова Екатерина Игоревна - к.Х.н, старший научный сотрудник, Саратовский национальный исследовательский государственный университет им. Н.Г. Чернышевского, Саратов

Наумова Галина Николаевна - магистрант кафедры аналитической химии и химической экологии, Саратовский национальный исследовательский государственный университет им. Н.Г. Чернышевского, Саратов
17. Martemiyanov D.V., Galanov A.I., Yurmazova T.A., National Research Tomsk Polytechnic University, 2013, Vol. 8, pp. 666-670.

18. Sukharev Y.I., Krupnova T.G., Grigorieva E.A., Titova E.N. et al., Proceedings of the Chelyabinsk Scientific Center of the Ural Branch of the Russian Academy of Sciences. Series: Chemistry and Bioecology, 2005, Vol. 3, pp. 80-84.

19. Taubaeva E.S., Jusipbekov U.Zh., Zhunusov S.M., Bulletin of the Kazan Technical University, 2010, Vol. 6, pp. 74-165.

20. Vigdorovich V.I., Tsigankova L.E., Akulov A.I., Sorbtsionnye $i$ khromatograficheskie protsessy,. 2011, Vol. 11, No. 2, pp. 256-262.

21. Gorelnikova E.A., Kovaleva S.V., Karpunina L.V., Splyukhin V.P. et al., Agrarian scientific journal. Ser. Natural Sciences, 2016, No. 11 , pp. 18-21.

22. Lamskova M.I., Novikov A.E., Bulletin of Volgograd State Technical University, 2014, Vol. 7, No. 1, pp. 77-80.

23. Venig C.B., Sergeantov V.G., Chernova R.K., Doronin S.Yu. et al., Butlerov Communications, 2014, Vol. 39, No. 8, pp. 17-26.

Venig Sergey B. - doctor of physical mathematical sciences, professor, department of materials science, technology and quality management, Saratov national research state university of N. G. Chernyshevsky, Saratov, E-mail: sergey.venig@mail.ru

Chernova Rimma K. - doctor of chemical sciences, professor of the department of analytical chemistry and chemical ecology of chemical faculty, Saratov national research state university of N. G. Chernyshevsky, Saratov, E-mail: chernov-ia@yandex.ru

Serzhantov Victor G. - candidate of physical mathematical sciences, head of the corporate departament of sorbtionmaterials, Saratov national research state university of N. G. Chernyshevsky, Saratov, E-mail: serzhantov55@mail.ru

Splyukhin Vladimir P. - assistant of the corporate departament of sorbtionmaterials, Saratov national research state university of N. G. Chernyshevsky, Saratov, Email: spluhinvp@mail.ru

Selifonova Ekaterina I. - Candidate of Chemical Sciences, Senior research associate, Saratov national research state university of N. G. Chernyshevsky, Saratov, E-mail: selif-ei@yandex.ru

Naumova Galina N. - student of the department of analytical chemistry and chemical ecology, Saratov national research state university of N. G. Chernyshevsky, Saratov, E-mail: naumova.galinka.93@mail.ru 